\title{
POLE PLACEMENT DESIGN OF DECENTRALIZED OUTPUT FEEDBACK POWER SYSTEM STABILIZERS USING HYBRID DIFFERENTIAL EVOLUTION
}

\author{
Yung-Sung Chuang \\ Associate Professor, Department of Electrical Engineering, Ming Hsin University of Science and Technology, Hsin \\ Feng, Hsin Chu, Taiwan, R.O.C. \\ Chi-Jui Wu \\ Professor, Department of Electrical Engineering, National Taiwan University of Science and Technology, Taipei, \\ Taiwan, R.O.C., cjwu@mouse.ee.ntust.edu.tw \\ Shu-Chen Wang \\ Graduated student, Department of Electrical Engineering, National Taiwan Ocean University, Keelung, Taiwan, R.O.C. \\ Pei-Hwa Huang \\ Associate Professor, Department of Electrical Engineering, National Taiwan Ocean University, Keelung, Taiwan, R.O.C.
}

Follow this and additional works at: https://jmstt.ntou.edu.tw/journal

Part of the Electrical and Computer Engineering Commons

\section{Recommended Citation}

Chuang, Yung-Sung; Wu, Chi-Jui; Wang, Shu-Chen; and Huang, Pei-Hwa (2007) "POLE PLACEMENT DESIGN OF DECENTRALIZED OUTPUT FEEDBACK POWER SYSTEM STABILIZERS USING HYBRID DIFFERENTIAL EVOLUTION," Journal of Marine Science and Technology. Vol. 15: Iss. 4, Article 9.

DOI: 10.51400/2709-6998.2051

Available at: https://jmstt.ntou.edu.tw/journal/vol15/iss4/9

This Research Article is brought to you for free and open access by Journal of Marine Science and Technology. It has been accepted for inclusion in Journal of Marine Science and Technology by an authorized editor of Journal of Marine Science and Technology. 


\title{
POLE PLACEMENT DESIGN OF DECENTRALIZED OUTPUT FEEDBACK POWER SYSTEM STABILIZERS USING HYBRID DIFFERENTIAL EVOLUTION
}

\author{
Yung-Sung Chuang*, Chi-Jui Wu**, Shu-Chen Wang***, and Pei-Hwa Huang****
}

\begin{abstract}
Key words: power system stabilizer, electromechanical mode, pole placement, hybrid differential evolution, power system dynamics.
\end{abstract}

\begin{abstract}
The hybrid differential evolution (HDE) has been used to investigate a novel decentralized pole placement design method of output feedback power system stabilizers. Since the local output variables are used as the feedback signals, the stabilizers could be easily implemented. In the design procedures, it wants to place the electromechanical modes within a designated region in the complex variable plane. The HDE method is originally an optimal searching approach. If all electromechanical modes have been moved to the specified region at the convergent steps, the objective function will reach zero, which is the minimum value. The objective function is chosen to ensure the real parts and damping ratios of electromechanical modes. A test power system is used to reveal the goodness of this method. The computation time and convergent characteristic of this approach are better, compared to the differential evolution and genetic algorithm. Since several operating conditions can be considered simultaneously in the determination of stabilizer parameters, the damping forces of the stabilizers could be ensured under a wider range of operating conditions. The coherency measures are also proposed to evaluate the relative behaviors between any pair of generators of the system with and without stabilizers.
\end{abstract}

\section{INTRODUCTION}

The dynamic stability characteristics of a power system are dominantly affected by the location of elec-

Paper Submitted 09/22/06, Accepted 01/17/07. Author for Correspondence: Chi-Jui Wu. E-mail: cjwu@mouse.ee.ntust.edu.tw

*Associate Professor, Department of Electrical Engineering, Ming Hsin University of Science and Technology, Hsin Feng, Hsin Chu, Taiwan, R.O.C.

**Professor, Department of Electrical Engineering, National Taiwan University of Science and Technology, Taipei, Taiwan, R.O.C.

***Graduated student, Department of Electrical Engineering, National Taiwan Ocean University, Keelung, Taiwan, R.O.C.

****Associate Professor, Department of Electrical Engineering, National Taiwan Ocean University, Keelung, Taiwan, R.O.C. tromechanical modes. It is sufficient that all of electromechanical modes are placed in a suitable region in the complex s-plane to ensure damping effects on low frequency oscillations. Power system stabilizers (PSSs) have been widely used to increase the damping ratios of electromechanical modes. Recently, design technology has been focused on the question of how to tune the parameters of PSSs in order to obtain optimal dynamic stability characteristics. Those include the optimization method using eigenvalue analysis [7], genetic design using simulated annealing optimization algorithms [2], probabilistic approach [14], tabu search algorithm [4], particle-swarm-optimization technique [3], and the genetic algorithm [1].

The method of hybrid differential evolution (HDE) is one of the best evolutionary algorithms for solving non-linear optimization problems $[9,11]$. A lot of literatures have recorded the HDE algorithm applications. They have been applied to the optimal control problem of a bio-process system [6]. Estimating the kinetic model parameters using HDE was presented in other literature [15]. This method was also employed for plant scheduling and planning to solve the decisionmaking problems of the manufacturing industry [10]. The improved HDE method for distribution systems has been used to reduce power loss and enhance the voltage profile [13]. This method may determine the optimal capacitor location of a radial distribution feeder [12].

The HDE method is applied in this paper to tune the decentralized output feedback PSSs. The terminal voltage, output active power, speed deviation, and rotor angle of the local generator are used as feedback signals, considering the implementation requirement. The optimal design technology of the HDE is used in this paper for the pole placement design of PSSs. Its aim is to move all of electromechanical modes in a region in the complex variable plane. The objective function is selected to ensure the location of real parts and damping ratios of all electromechanical modes. At the end of the iterative procedures, all of electromechanical modes 
will be moved to this region if the objective function converges to zero. Since optimal searching is used, several operating conditions can be considered simultaneously so that the PSSs could work well under a wider range of operating conditions. The computation time and convergence characteristic of this approach are better, compared to the differential evolution and genetic algorithm. From the design and simulation results of a multi-machine power system, the proposed PSSs can allow the generators to have enough damping effects when there are tripping line disturbances. The coherency measures are also proposed to evaluate the relative behaviors between any pair of generators of the system with and without stabilizers.

\section{HYBRID DIFFERENTIAL EVOLUTION}

A nonlinear optimization problem can be expressed as

$$
\text { Minimize } M(\underline{X})
$$

Subject to

$$
\begin{array}{ll}
g_{k}(\underline{X}) \leq 0 & k=1, \ldots, n_{g} \\
h_{k}(\underline{X})=0 & k=1, \ldots, n_{h}
\end{array}
$$

where $M(\underline{X})$ : objective function of variable vector $\underline{X}$,

$$
\underline{X}=\left[X_{1}, X_{2}, \ldots, X_{j}, \ldots, X_{D}\right]^{t}
$$

$g_{k}(\underline{X})$ : inequality constraints.

$h_{k}(\underline{X})$ : equality constraints.

Differential evolution is a parallel direct search method for minimizing nonlinear and non-differential objective functions. The fitness of an offspring is determined by one-to-one competition with the corresponding parent. The solution procedures are given as follows.

\section{Step 1. Initialization}

Several initial populations $\underline{X}_{i}^{0}, i=1,2, \ldots, N_{P}$ are randomly selected. They should cover the entire search space uniformly. The elements of each individual $\underline{X}_{i}^{0}$ are given by

$$
\begin{aligned}
& X_{j i}^{0}=X_{j}^{\min }+\rho_{i}\left(X_{j}^{\max }-X_{j}^{\min }\right), \\
& j=1,2, \ldots, D, i=1,2, \ldots, N_{P}
\end{aligned}
$$

where $\rho_{i} \in[0,1]$ is a random number, and $N_{P}$ is the population size. $X_{j}^{\min }$ and $X_{j}^{\max }$ are the lower and upper bounds of the variable $X_{j}$, respectively.

\section{Step 2. Mutation operation}

At generation $\mathrm{G}$, each mutant vector is generated based on the corresponding present individual $\underline{X}_{i}^{G}$ by

$$
\underline{U}_{i}^{G+1}=\underline{X}_{i}^{G}+F\left(\underline{X}_{r 1}^{G}-\underline{X}_{r 2}^{G}\right), i=1,2, \ldots, N_{p}
$$

where $i \neq r 1, i \neq r 2$, and $r 1, r 2 \in\left\{1,2, \ldots, N_{P}\right\} . F \in[0$, 1] is a scalar factor. $\underline{X}_{r 1}^{G}$ and $\underline{X}_{r 2}^{G}$ are two randomly selected individuals.

\section{Step 3. Crossover operation}

To extend the diversity of individuals in the next generation, the perturbed individual

$$
\underline{-}_{i}^{G+1}=\left[U_{1 i}^{G+1}, U_{2 i}^{G+1}, \ldots, U_{j i}^{G+1}, \ldots, U_{D i}^{G+1}\right]^{t}
$$

and the present individual $\underline{X}_{i}^{G}=\left\lfloor X_{1 i}^{G}, X_{2 i}^{G}, \ldots, X_{j i}^{G}, \ldots,\left.X_{D i}^{G}\right|^{t}\right.$ are mixed to yield the trial vector

$$
\hat{U}_{i}^{G+1}=\left[\hat{U}_{1 i}^{G+1}, \hat{U}_{2 i}^{G+1}, \ldots, \hat{U}_{j i}^{G+1}, \ldots, \hat{U}_{D i}^{G+1}\right]^{t}
$$

where

$$
\begin{gathered}
\hat{U}_{j i}^{G+1}=\left\{\begin{array}{l}
X_{j i}^{G}, \text { if a random number }>C_{R} \\
U_{j i}^{G+1}, \text { otherwise }
\end{array},\right. \\
j=1,2, \ldots, D, i=1,2, \ldots, N_{P}
\end{gathered}
$$

where $D$ is also the number of genes. $C_{R} \in[0,1]$ is the crossover factor and must be set by the user.

\section{Step 4. Evaluation and selection}

The parent is replaced by its offspring in the next generation if the fitness of the latter is better. Contrarily, the parent is retained. The first step is one-to-one competition. The next step chooses the best individual, $X_{b}^{G+1}$ in the population. That is

$$
\underline{X}_{i}^{G+1}=\arg -\min \left\{M\left(\underline{X}_{i}^{G}\right), M\left(\underline{\hat{U}}_{i}^{G+1}\right)\right\}, i=1,2, \ldots, N_{P}
$$




$$
\underline{X}_{b}^{G+1}=\arg -\min \left\{M\left(\underline{X}_{i}^{G+1}\right)\right\}, i=1,2, \ldots, N_{P}
$$

where $\arg$-min means the argument of the minimum.

The above steps are repeated until the maximum iteration number or the desired fitness is obtained. In general, a faster descent usually leads to a local minimum or a premature convergence. Conversely, diversity guarantees a high probability of obtaining the global optimum. The trade-off can be obtained by slightly lowering the scaling factor $F$ and by increasing the population size $N_{P}$. However, more computation time is required. The migrant and accelerated operations in HDE are used to overcome the local minimum solution and time consumption. The migrant and accelerating operations are inserted in the differential evolution.

\section{Step 5. Migrant operation if necessary}

For increasing search space exploration, a migration operation is introduced to regenerate a diverse population of individuals. The migrant individuals are selected on a "best individual" basis $\underline{X}_{b}^{G+1}$. The $\mathrm{j}^{\text {th }}$ gene of $\underline{X}_{i}$ is regenerated by

$X_{j i}^{G+1}=\left\{\begin{array}{l}X_{j b}^{G+1}+\rho_{1}\left(X_{j}^{\min }-X_{j b}^{G+1}\right), \text { if } \rho_{2}<\frac{X_{j b}^{G+1}-X_{j}^{\min }}{X_{j}^{\max }-X_{j}^{\min }} \\ X_{j b}^{G+1}+\rho_{1}\left(X_{j}^{\max }-X_{j b}^{G+1}\right), \text { otherwise }\end{array}\right.$

where $\rho_{1}$ and $\rho_{2}$ are randomly generated numbers uniformly distributed in $[0,1]$. The migrant population will not only become a set of newly promising solutions, but also avoid the local minimum trap.

The migrant operation is performed only if a measure fails to match the desired population diversity tolerance. The measure in this study is defined as

$$
u=\frac{\left[\sum_{\substack{i=1 \\ i \neq b}}^{N_{P}} \sum_{j=1}^{D} \eta_{j i}\right]}{D\left(N_{P}-1\right)}<\varepsilon_{1}
$$

where

$$
\eta_{j i}=\left\{\begin{array}{l}
1, \text { if }\left|\frac{X_{j i}^{G+1}-X_{j b}^{G+1}}{X_{j b}^{G+1}}\right|>\varepsilon_{2} \\
0, \text { otherwise }
\end{array}\right.
$$

parameters $\varepsilon_{1} \in[0,1]$ and $\varepsilon_{2} \in[0,1]$ express the desired tolerance of the population diversity and the gene diversity with regard to the best individual, respectively. Here $\eta_{j i}$ is defined as an index of the gene diversity. A zero $\eta_{j i}$ means that the $\mathrm{j}^{\text {th }}$ gene of the $\mathrm{i}^{\text {th }}$ individual is close to the $j^{\text {th }}$ gene of the best individual. If the degree of population diversity $u$ is smaller than $\varepsilon_{1}$, the HDE performs migration to generate a new population to escape the local point. Otherwise, HDE breaks off the migration, which maintains an ordinary search direction.

\section{Step 6. Accelerated operation if necessary}

When the fitness in the present generation is no longer improved using the mutation and crossover operations, a descent method is then applied to push the present best individual toward a better point. Thus, the acceleration operation can be expressed as

$$
\underline{\hat{X}}_{b}^{G+1}=\left\{\begin{array}{l}
\underline{X}_{b}^{G+1}, \text { if } M\left(\underline{X}_{b}^{G+1}\right)<M\left(\underline{X}_{b}^{G}\right) \\
\underline{X}_{b}^{G+1}-\alpha \nabla M\left(\underline{X}_{b}^{G+1}\right), \text { otherwise }
\end{array}\right.
$$

The gradient of the objective function, $\nabla M\left(\underline{X}_{b}^{G+1}\right)$, can be approximately calculated with a finite difference. The step size $\alpha \in[0,1]$ is determined according to the decent property. Firstly, $\alpha$ is set to unity. The objective function $M\left(\underline{X}_{b}^{G+1}\right)$ is then compared with $M\left(\underline{X}_{b}^{G+1}\right)$. If the decent property is achieved $\underline{X}_{b}^{G+1}$, becomes a candidate in the next generation, and is added into this population to replace the worst individual. On the other hand, if the decent requirement fails, the step size is reduced, for example, 0.5 or 0.7 . The decent search method is repeated to find the optimal $\underline{X}_{b}^{G+1}$, called $\underline{X}_{b}^{N}$, at the $(G+1)^{\text {th }}$ generation. This result shows the objective function $M\left(X_{b}^{N}\right)$ should be at least equal or smaller than $M\left(\underline{X}_{b}^{G+1}\right)$.

\section{TUNING OF PSS}

\section{Power system description}

Determining the parameters of PSSs for an Ngenerator power system should consider various loading conditions. In considering a linearized time-invariant system, the equations of generator $i$ in the two-axis 
model are expressed by

$$
\begin{gathered}
\dot{\mathbf{x}}_{i}(\mathbf{t})=\mathbf{A}_{i i} \mathbf{x}_{i}(\mathbf{t})+\sum_{j=1, j \neq i}^{N} \mathbf{A}_{i j} \mathbf{x}_{j}(\mathbf{t})+\mathbf{B}_{i i} \mathbf{u}_{i}(\mathbf{t}) \\
i=1,2, \ldots, N
\end{gathered}
$$

where $\mathbf{x}_{\mathbf{i}}(t)=\left[\Delta E_{d i}^{\prime} \Delta E_{q i}^{\prime} \Delta \omega_{i} \Delta \delta_{i} \Delta E_{F D i} \Delta V_{S i}\right]^{t}$ is the state vector, $\Delta E_{d i}^{\prime}$ and $\Delta E_{q i}^{\prime}$ are the $\mathrm{d}$-axis and q-axis transient voltages, respectively, and $\Delta \omega_{i}$ and $\Delta \delta_{i}$ are the rotor speed and angle, respectively, $\Delta E_{F D i}$ is the field voltage, $\Delta V_{S i}$ is the output signal of stabilizing transformer. The diagram of static excitation is given in Figure 1.

\section{Output feedback PSS}

The output feedback PSSs are considered as shown in Figure 2. Since only local feedback signals are used, the control scheme is decentralized. The output of the PSS is

$$
V_{P S S}(t)=K_{1} \Delta V_{t}(t)+K_{2} \Delta P_{e}(t)+K_{3} \Delta \omega(t)+K_{4} \Delta \delta(t)
$$

The parameters $K_{1}, K_{2}, K_{3}$ and $K_{4}$ are to be determined. $V_{t}$ and $P_{e}$ are the terminal voltage and active power of generator, respectively.

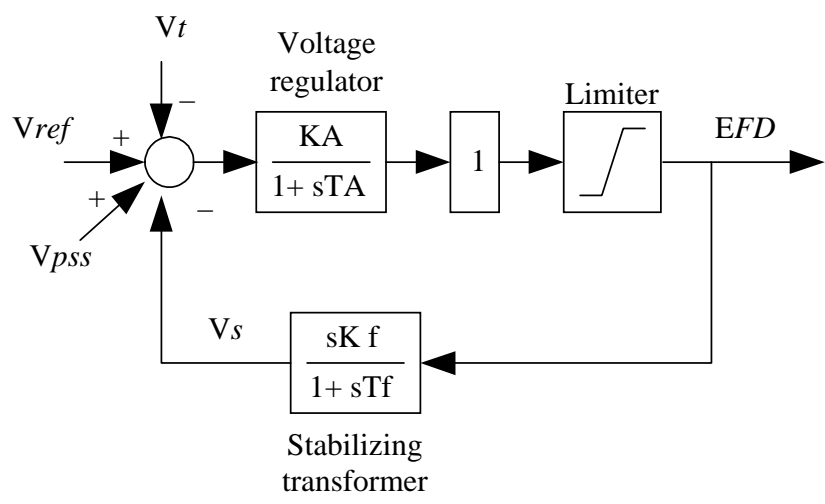

Fig. 1. Block diagram of static excitation system.

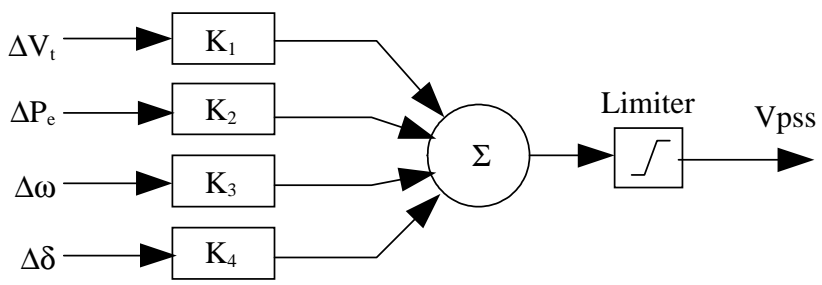

Fig. 2. Output feedback power system stabilizer.

\section{Objective function}

The objective function is selected so that all electromechanical modes can be moved to the specified region as shown in Figure 3. It is required that $\sigma_{i, j} \leq \sigma_{0}$ and $\zeta_{i, j} \geq \zeta_{0}$, where $\sigma_{i, j}$ and $\zeta_{i, j}$ are the real part and damping ratio of the $i^{\text {th }}$ electromechanical mode under the $\mathrm{j}^{\text {th }}$ operating condition. Then the objective function for an $\mathrm{N}$-generator system is given as

$$
\begin{aligned}
& M=\sum_{j=1}^{n p} \sum_{i=1}^{N}\left(\sigma_{0}-\sigma_{i, j}\right)^{2}+\sum_{j=1}^{n p} \sum_{i=1}^{N}\left(\zeta_{0}-\zeta_{i, j}\right)^{2} \\
& \text { for } \sigma_{i, j} \geq \sigma_{0} \text { and } \zeta_{i, j} \leq \zeta_{0}
\end{aligned}
$$

where $n p$ is the number of operating points considered in the design process. The system stability condition is determined by $\sigma_{0}$ and $\xi_{0}$. In the design procedure using HDE, the population size $N_{P}$ is selected to be 5 , the scalar factor $F$ to be 0.01 , and the crossover factor $C_{R}$ to be 0.5 . The design flowchart is shown in Figure 4.

\section{EXAMPLE: A MULTI-MACHINE POWER SYSTEM}

Consider a multi-machine power system as shown in Figure 5, where bus 1 is assumed to be an infinite bus. Generators 2-6 are equipped with static exciters. Four static loads are connected to bus $8,11,13$ and, 14, respectively. The system data are given in Appendix. The active power and terminal voltage of generators under three operating conditions are given in Table 1.

In Table 2, for the system without PSS under operation condition 1 (normal load), some damping characteristics of electromechanical modes are poor. From time domain simulation results, the poor damping electromechanical modes are caused by generators 2,5 , and 6 .

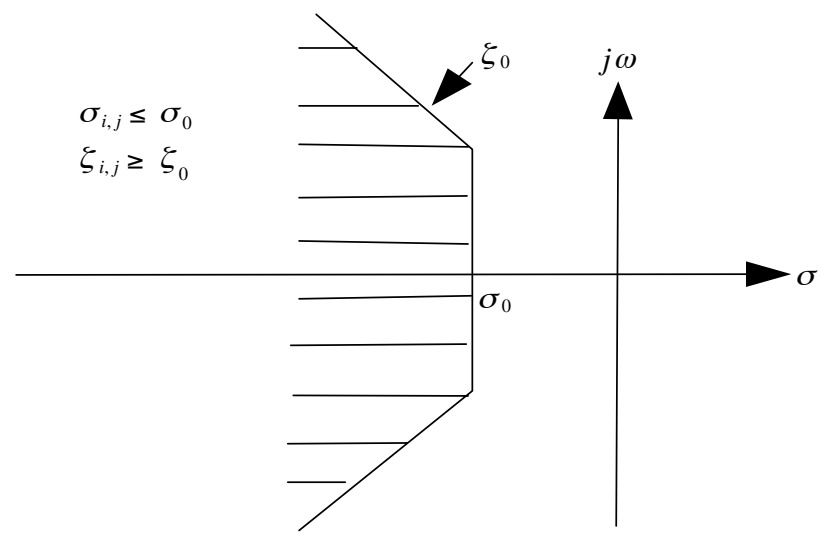

Fig. 3. A sector in the s-plane where $\sigma_{i, j} \leq \sigma_{0}$ and $\zeta_{i, j} \geq \zeta_{0}$. 


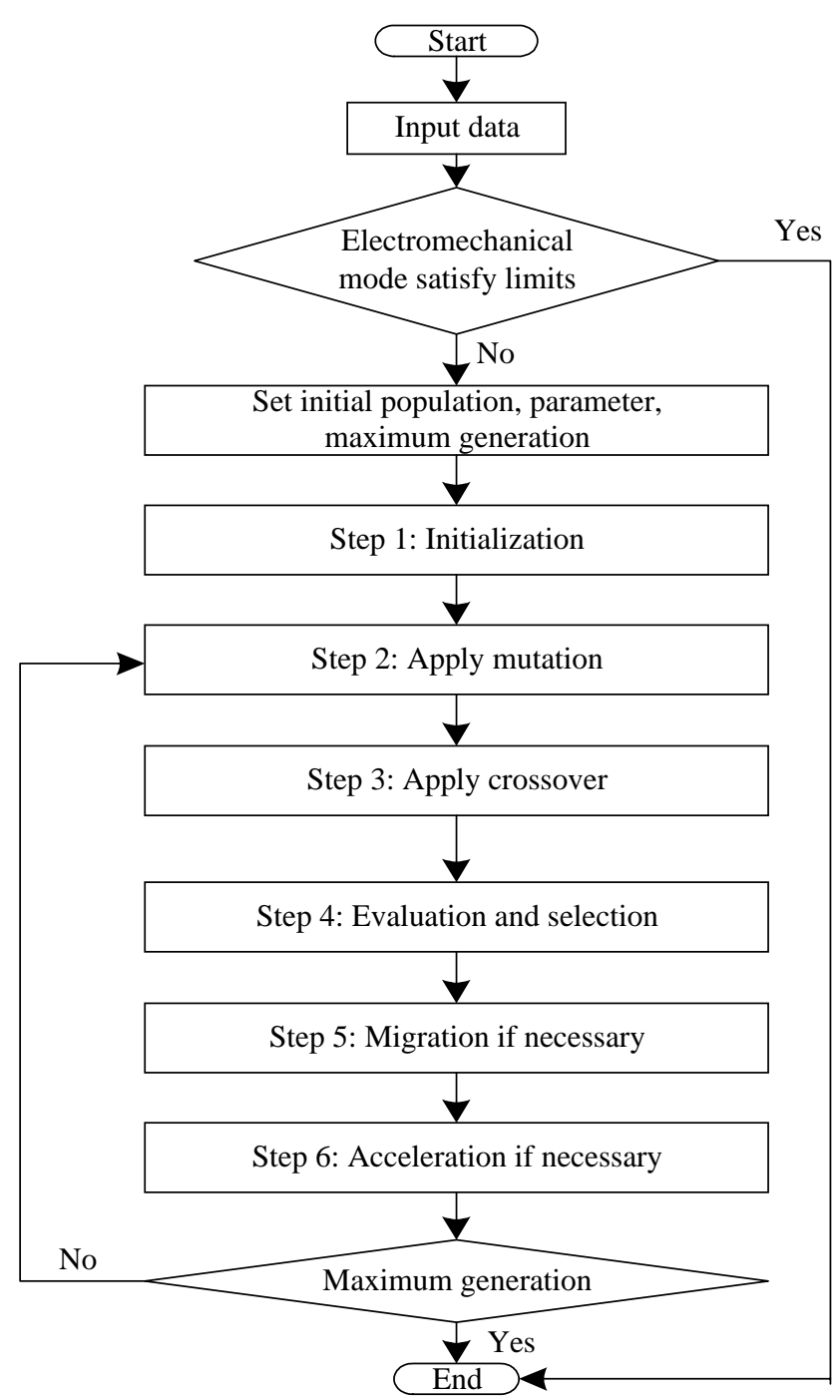

Fig. 4. Flowchart of design of PSS using HDE.

\section{Comparison of HDE, DE, and GA}

In the designing PSSs of generators 2, 5, and 6 under operation condition 1 using DE, GA, and HDE methods, it is selected that $\sigma_{0}=-1$ and $\xi_{0}=0.1$. All objective functions have converged as revealed in Figure 6. It is also shown that DE, GA, and HDE take $69,918,231$ iteration steps to converge, respectively. However, only the objective functions of GA and HDE reach zero as shown in Table 3. It means that all electromechanical modes are placed in the assignment region, but does not ensure that each electromechanical mode using HDE is better than that using GA. The computation time is evaluated by the CPU time on a Pentium III $2.4 \mathrm{GHz}$ computer. It indicates that HDE is faster than GA. Although the DE is the fastest one, it is convergent to a local optimal solution and has a larger

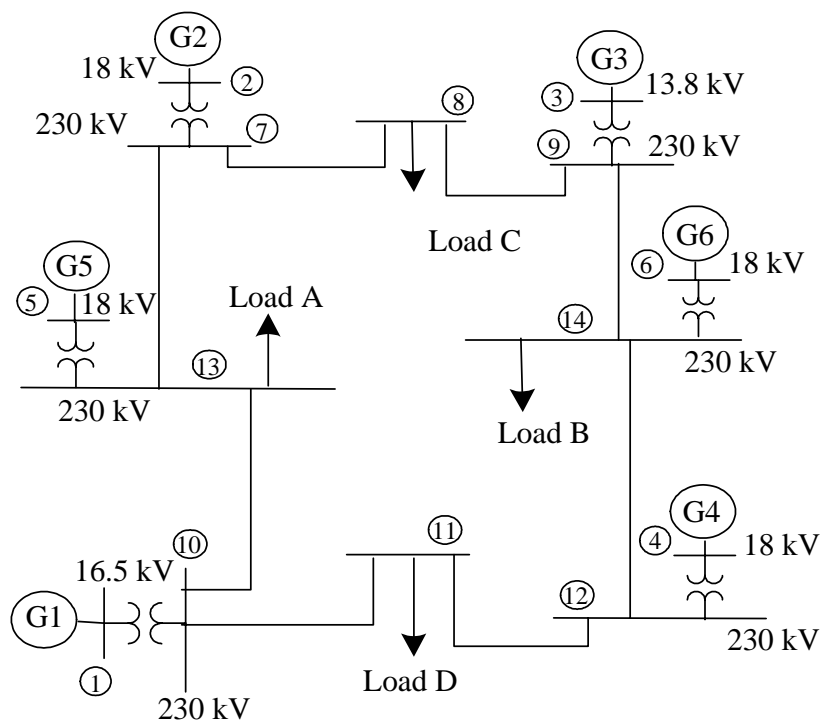

Fig. 5. A multi-machine power system diagram.

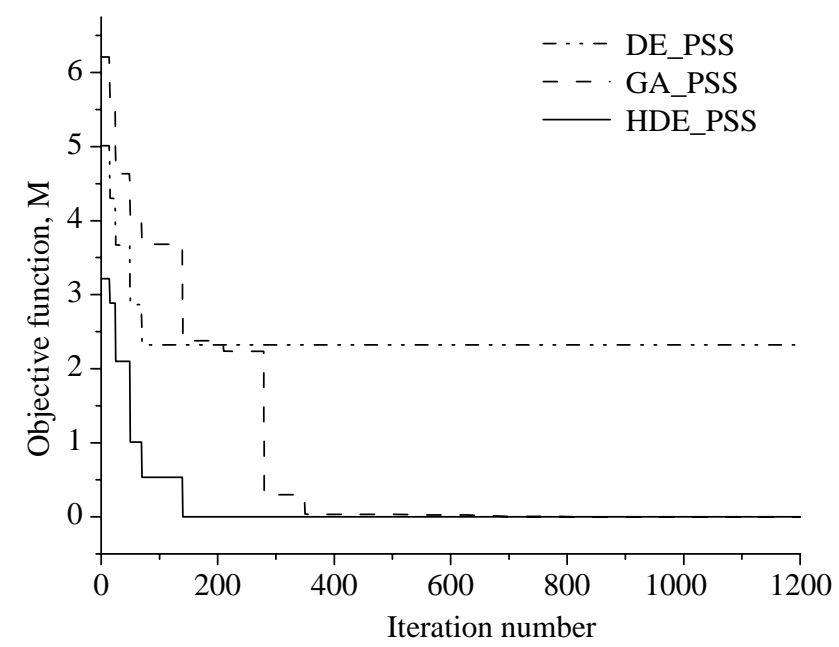

Fig. 6. Convergent characteristics of objective functions using DE, GA, and HDE under operating condition 1.

convergent objective function value. The design results of the parameter values of PSSs are given in rows 2-4 of Table 4. The electromechanical modes of the system with DE_PSS, GA_PSS, and HDE_PSS are also tabulated in Table 2.

In the time domain simulations, nonlinear differential equations must be used to examine the damping effects of PSSs. The tripping of line 7-13 is used as a larger disturbance. Simulation results are given in Figure 7 for generators 2, 5, and 6. The system with the HDE_PSS has better responses. 
Table 1. Operating conditions

\begin{tabular}{|c|c|c|c|c|c|c|c|c|c|c|}
\hline \multirow[t]{2}{*}{ Loading (pu) } & \multicolumn{2}{|c|}{$\mathrm{G} 2$} & \multicolumn{2}{|c|}{ G3 } & \multicolumn{2}{|c|}{ G4 } & \multicolumn{2}{|c|}{ G5 } & \multicolumn{2}{|c|}{ G6 } \\
\hline & $\begin{array}{c}\mathrm{P}_{\mathrm{g}} \\
(\mathrm{pu})\end{array}$ & $\begin{array}{c}\mathrm{V}_{\mathrm{t}} \\
(\mathrm{pu})\end{array}$ & $\begin{array}{c}\mathrm{P}_{\mathrm{g}} \\
(\mathrm{pu})\end{array}$ & $\begin{array}{c}\mathrm{V}_{\mathrm{t}} \\
(\mathrm{pu})\end{array}$ & $\begin{array}{c}\mathrm{P}_{\mathrm{g}} \\
(\mathrm{pu})\end{array}$ & $\begin{array}{c}\mathrm{V}_{\mathrm{t}} \\
(\mathrm{pu})\end{array}$ & $\begin{array}{c}\mathrm{P}_{\mathrm{g}} \\
(\mathrm{pu})\end{array}$ & $\begin{array}{c}\mathrm{V}_{\mathrm{t}} \\
(\mathrm{pu})\end{array}$ & $\begin{array}{c}\mathrm{P}_{\mathrm{g}} \\
(\mathrm{pu})\end{array}$ & $\begin{array}{r}\mathrm{V}_{\mathrm{t}} \\
(\mathrm{pu})\end{array}$ \\
\hline $\begin{array}{l}\text { Operating } \\
\text { condition } 1 \\
\mathrm{~S}_{\mathrm{LA}}=2.5+\mathrm{j} 1.0 \\
\mathrm{~S}_{\mathrm{LB}}=1.8+\mathrm{j} 0.6 \\
\mathrm{~S}_{\mathrm{LC}}=1+\mathrm{j} 0.35 \\
\mathrm{~S}_{\mathrm{LD}}=1+\mathrm{j} 0.35 \\
\end{array}$ & 1.63 & 1.03 & 0.85 & 1.03 & 1.32 & 1.03 & 1.32 & 1.03 & 1.32 & 1.03 \\
\hline $\begin{array}{l}\text { Operating } \\
\text { condition } 2 \\
\mathrm{~S}_{\mathrm{LA}}=3+\mathrm{j} 1.2 \\
\mathrm{~S}_{\mathrm{LB}}=2.16+\mathrm{j} 0.72 \\
\mathrm{~S}_{\mathrm{LC}}=1.2+\mathrm{j} 0.42 \\
\mathrm{~S}_{\mathrm{LD}}=1.2+\mathrm{j} 0.42\end{array}$ & 1.96 & 1.04 & 1.02 & 1.04 & 1.58 & 1.04 & 1.58 & 1.04 & 1.58 & 1.04 \\
\hline $\begin{array}{l}\text { Operating } \\
\text { condition } 3 \\
S_{\mathrm{LA}}=1+\mathrm{j} 0.4 \\
\mathrm{~S}_{\mathrm{LB}}=0.72+\mathrm{j} 0.24 \\
\mathrm{~S}_{\mathrm{LC}}=0.4+\mathrm{j} 0.14 \\
\mathrm{~S}_{\mathrm{LD}}=0.4+\mathrm{j} 0.14\end{array}$ & 0.65 & 1.01 & 0.34 & 1.01 & 0.53 & 1.01 & 0.53 & 1.01 & 0.53 & 1.01 \\
\hline
\end{tabular}

Table 2. Electromechanical modes under operating condition 1

\begin{tabular}{cccc}
\hline $\begin{array}{c}\text { Without } \\
\text { PSS }\end{array}$ & DE & GA & HDE \\
\hline $\begin{array}{c}\text { Eigenvalue } \\
\text { (Damping ratio) }\end{array}$ & $\begin{array}{c}\text { Eigenvalue } \\
\text { (Damping ratio) }\end{array}$ & $\begin{array}{c}\text { Eigenvalue } \\
\text { (Damping ratio) }\end{array}$ & $\begin{array}{c}\text { Eigenvalue } \\
\text { (Damping ratio) }\end{array}$ \\
\hline$-0.57 \pm \mathrm{j} 9.96(0.057)$ & $-0.17 \pm \mathrm{j} 21.96(0.008)$ & $-1.76 \pm \mathrm{j} 17.43(0.1)$ & $-1.08 \pm \mathrm{j} 8.74(0.12)$ \\
$-1.15 \pm \mathrm{j} 14.2(0.081)$ & $-1.77 \pm \mathrm{j} 14.83(0.12)$ & $-1.39 \pm \mathrm{j} 14.00(0.1)$ & $-1.42 \pm \mathrm{j} 13.31(0.11)$ \\
$-1.24 \pm \mathrm{j} 15.1(0.082)$ & $-1.18 \pm \mathrm{j} 12.89(0.09)$ & $-2.76 \pm \mathrm{j} 12.33(0.21)$ & $-1.55 \pm \mathrm{j} 14.02(0.11)$ \\
$-0.97 \pm \mathrm{j} 13.0(0.074)$ & $-1.13 \pm \mathrm{j} 9.10(0.12)$ & $-1.41 \pm \mathrm{j} 10.95(0.13)$ & $-1.31 \pm \mathrm{j} 12.94(0.1)$ \\
$-0.001 \pm \mathrm{j} 6(0.0002)$ & $-0.85 \pm \mathrm{j} 5.24(0.16)$ & $-1.00 \pm \mathrm{j} 5.29(0.19)$ & $-3.23 \pm \mathrm{j} 4.03(0.6)$ \\
\hline
\end{tabular}

\section{Comparison of five control schemes}

Five control schemes are compared.

Scheme 1: without PSS

Scheme 2: Generators 2, 5, and 6 are equipped with the conventional PSSs, whose parameter values, designed by phase compensation and root locus analysis, are given in Table 5 [8].

Scheme 3: Generators 2 and 6 are equipped with HDE PSSs. The parameter values are designed under operating condition 1.

Scheme 4: Generators 2, 5, and 6 are equipped with
HDE PSSs. The parameter values are designed under operating condition 1.

Scheme 5: Generator 2, 5, and 6 are equipped with HDE PSSs. The parameter values are designed when three operating conditions are considered simultaneously.

For the system without PSS, the electromechanical modes are tabulated in the third row of Table 6 for three operating conditions. Generators 2, 5, and 6 have small damping ratio. In the design of schemes $3-4$, it is selected that $\sigma_{0}=-1$ and $\zeta_{0}=0.1$. The convergent characteristics of objective functions are revealed in Figure 8 . Only scheme 4 and scheme 5 can reach zero. 
Table 3. Comparison of DE, GA, and HDE under operating condition 1

\begin{tabular}{cccccc}
\hline & $\begin{array}{c}\text { Objective } \\
\text { function } \\
(\mathrm{pu})\end{array}$ & $N_{P}$ & $\begin{array}{c}\mathrm{CPU} \text { time } \\
(\mathrm{sec})\end{array}$ & $\begin{array}{c}C_{R} \\
\left(P_{C}\right)\end{array}$ & $\begin{array}{c}\mathrm{F} \\
\left(P_{m}\right)\end{array}$ \\
\hline $\mathrm{DE}$ & 2.32 & 5 & 5.82 & 0.5 & 0.01 \\
$\mathrm{GA}$ & 0 & 5 & 83.49 & 0.5 & 0.01 \\
$\mathrm{HDE}$ & 0 & 5 & 36.85 & 0.5 & 0.01 \\
\hline
\end{tabular}

Table 4. Parameter values of PSSs designed under operating condition 1

\begin{tabular}{cccccc}
\hline & & $K_{1}$ & $K_{2}$ & $K_{3}$ & $K_{4}$ \\
\hline \multirow{4}{*}{ DE } & G2 & -48.8 & -25.1 & 30.4 & 13.4 \\
& G5 & 3.4 & -41.1 & -5.7 & -37.9 \\
& G6 & -38.1 & -34.9 & -5.3 & -2.4 \\
\hline \multirow{4}{*}{ GA } & G2 & -6.3 & 0.005 & 49.9 & -0.01 \\
& G5 & -49.0 & -25.2 & 39.9 & -24.0 \\
& G6 & -39.1 & -20.8 & -7.1 & 10.1 \\
\hline \multirow{4}{*}{ HDE } & G2 & -40.5 & 3.30 & 42.83 & 11.13 \\
& G5 & -37.3 & -7.12 & 15.59 & -9.84 \\
& G6 & -50 & -21.76 & 42.01 & -15.09 \\
\hline
\end{tabular}

The design results of PSSs using HDE are given in Table 7. The electromechanical modes of the system with schemes 2-5 under three operating conditions are also tabulated in Table 6. Figures 9-13 show the location of electromechanical modes in the complex s-plane of the system with scheme 1-5 under operation conditions 1-3. Since only operating condition 1 is considered in scheme 4 , some electromechanical modes of the system under other operating conditions can not remain in the designated region as shown in Figure 12. Since in the design of scheme 5, three operating conditions are considered simultaneously, the damping conditions under those operating conditions are all satisfied as shown in Figure 13.

The tripping of line 7-13 is also used as a larger

Table 5. The parameter of conventional PSSs

\begin{tabular}{ccccccc}
\hline & $K_{\mathbf{S}}$ & $\begin{array}{c}T_{\mathbf{1}} \\
(\mathrm{sec})\end{array}$ & $\begin{array}{c}T_{\mathbf{2}} \\
(\mathrm{sec})\end{array}$ & $\begin{array}{c}T_{\mathbf{3}} \\
(\mathrm{sec})\end{array}$ & $\begin{array}{c}T_{\mathbf{4}} \\
(\mathrm{sec})\end{array}$ & $\begin{array}{c}T_{\mathbf{5}} \\
(\mathrm{sec})\end{array}$ \\
\hline $\mathrm{G} 2$ & 25 & 0.25 & 0.05 & 0.5 & 0.06 & 0.5 \\
$\mathrm{G} 5$ & 25 & 0.25 & 0.05 & 0.5 & 0.06 & 0.5 \\
$\mathrm{G} 6$ & 25 & 0.25 & 0.05 & 0.5 & 0.06 & 0.5 \\
\hline
\end{tabular}

Table 6. Eigenvalues and damping ratios of electromechanical modes

\begin{tabular}{|c|c|c|c|c|c|c|}
\hline & \multicolumn{2}{|c|}{ Operation condition 1} & \multicolumn{2}{|c|}{ Operation condition 2} & \multicolumn{2}{|c|}{ Operation condition 3} \\
\hline & Eigenvalue & Damping ratio & Eigenvalue & Damping ratio & Eigenvalue & Damping ratio \\
\hline \multirow{5}{*}{ Scheme 1} & $-0.57 \pm j 9.96$ & 0.057 & $-0.42 \pm j 9.97$ & 0.04 & $-1.44 \pm j 9.70$ & 0.15 \\
\hline & $-1.15 \pm \mathrm{j} 14.2$ & 0.081 & $-0.84 \pm \mathrm{j} 14.1$ & 0.06 & $-1.93 \pm \mathrm{j} 14.1$ & 0.14 \\
\hline & $-1.24 \pm \mathrm{j} 15.1$ & 0.082 & $-1.08 \pm \mathrm{j} 15.3$ & 0.07 & $-2.18 \pm j 14.6$ & 0.15 \\
\hline & $-0.97 \pm \mathrm{j} 13.0$ & 0.074 & $-0.82 \pm \mathrm{j} 13.2$ & 0.06 & $-1.91 \pm \mathrm{j} 12.6$ & 0.15 \\
\hline & $-0.001 \pm \mathrm{j} 6$ & 0.0002 & $0.1 \pm \mathrm{j} 5.68$ & -0.02 & $-0.39 \pm \mathrm{j} 5.88$ & 0.07 \\
\hline \multirow{5}{*}{ Scheme 2} & $-1.09 \pm \mathrm{j} 12.76$ & 0.09 & $-1.29 \pm j 9.26$ & 0.14 & $-2.11 \pm \mathrm{j} 12.31$ & 0.17 \\
\hline & $-9.24 \pm \mathrm{j} 53.89$ & 0.17 & $-9.2 \pm j 54.13$ & 0.17 & $-2.64 \pm j 18.23$ & 0.14 \\
\hline & $-12.13 \pm \mathrm{j} 41.19$ & 0.28 & $-11.85 \pm j 42.56$ & 0.2 & $-4.4 \pm \mathrm{j} 13.42$ & 0.31 \\
\hline & $-8.94 \pm \mathrm{j} 55.51$ & 0.16 & $-8.79 \pm \mathrm{j} 56.08$ & 0.15 & $-3.94 \pm \mathrm{j} 13.66$ & 0.28 \\
\hline & $-1.36 \pm \mathrm{j} 9.01$ & 0.15 & $-0.96 \pm \mathrm{j} 9.26$ & 0.1 & $-1.38 \pm \mathrm{j} 9.5$ & 0.1 \\
\hline \multirow{5}{*}{ Scheme 3} & $-0.73 \pm \mathrm{j} 11.33$ & 0.06 & $-0.65 \pm \mathrm{j} 11.51$ & 0.06 & $-1.6 \pm j 10.66$ & 0.15 \\
\hline & $-1.0 \pm \mathrm{j} 14.02$ & 0.07 & $-0.9 \pm \mathrm{j} 14.25$ & 0.06 & $-2.0 \pm \mathrm{j} 14.47$ & 0.14 \\
\hline & $-2.77 \pm j 12.38$ & 0.22 & $-2.61 \pm j 12.62$ & 0.2 & $-3.11 \pm \mathrm{j} 12.94$ & 0.23 \\
\hline & $-0.81 \pm \mathrm{j} 15.38$ & 0.05 & $-0.61 \pm j 15.68$ & 0.04 & $-2.09 \pm \mathrm{j} 13.46$ & 0.15 \\
\hline & $-1.04 \pm \mathrm{j} 4.85$ & 0.21 & $-1.09 \pm \mathrm{j} 4.69$ & 0.23 & $-0.6 \pm j 5.72$ & 0.1 \\
\hline \multirow{5}{*}{ Scheme 4} & $-1.08 \pm j 8.74$ & 0.12 & $-0.97 \pm j 8.98$ & 0.11 & $-2.25 \pm j 8.58$ & 0.25 \\
\hline & $-1.42 \pm \mathrm{j} 13.31$ & 0.11 & $-1.45 \pm \mathrm{j} 16.36$ & 0.09 & $-1.9 \pm \mathrm{j} 15.4$ & 0.12 \\
\hline & $-1.55 \pm \mathrm{j} 14.02$ & 0.11 & $-1.61 \pm j 17.03$ & 0.09 & $-1.95 \pm \mathrm{j} 16$ & 0.12 \\
\hline & $-1.31 \pm \mathrm{j} 12.94$ & 0.1 & $-0.98 \pm j 13.19$ & 0.07 & $-2.09 \pm \mathrm{j} 12.49$ & 0.17 \\
\hline & $-3.23 \pm \mathrm{j} 4.03$ & 0.6 & $-3.09 \pm j 3.33$ & 0.68 & $-1.85 \pm \mathrm{j} 5.49$ & 0.32 \\
\hline \multirow{5}{*}{ Scheme 5} & $-1.32 \pm j 10.15$ & 0.13 & $-1.3 \pm j 10.34$ & 0.12 & $-2.05 \pm j 9.88$ & 0.2 \\
\hline & $-3.07 \pm \mathrm{j} 10.13$ & 0.29 & $-1.51 \pm \mathrm{j} 14.38$ & 0.1 & $-2.19 \pm \mathrm{j} 13.19$ & 0.16 \\
\hline & $-3.56 \pm \mathrm{j} 14.02$ & 0.25 & $-3.86 \pm \mathrm{j} 5.3$ & 0.6 & $-5.8 \pm \mathrm{j} 11.5$ & 0.45 \\
\hline & $-1.38 \pm \mathrm{j} 13.97$ & 0.1 & $-2.69 \pm j 10.51$ & 0.25 & $-3.67 \pm j 10.08$ & 0.34 \\
\hline & $-1.31 \pm \mathrm{j} 5.48$ & 0.23 & $-1.31 \pm \mathrm{j} 5.55$ & 0.23 & $-1.66 \pm \mathrm{j} 5.76$ & 0.28 \\
\hline
\end{tabular}



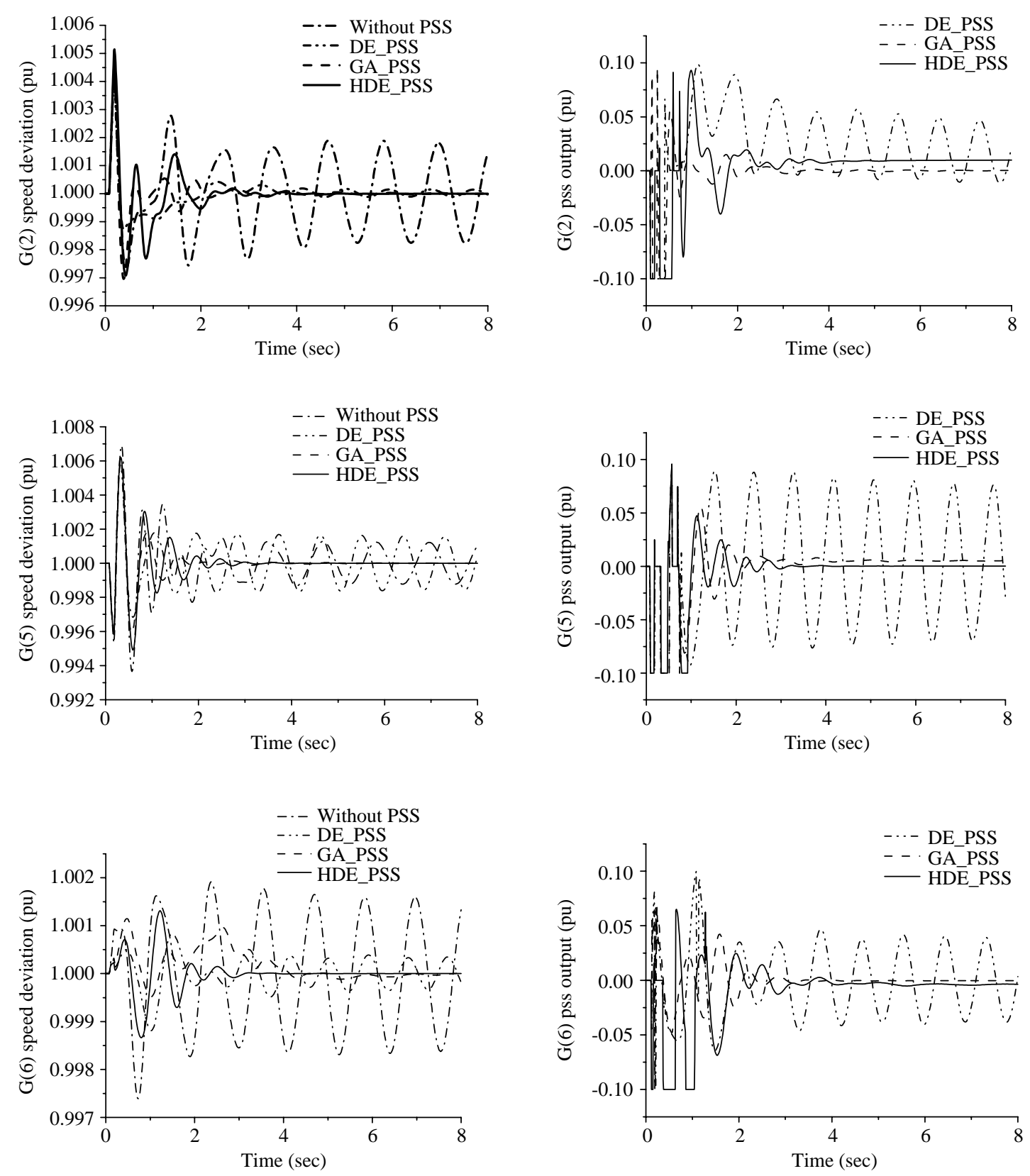

Fig. 7. Responses of Generators 2, 5, and 6 subjected to large disturbance under operating condition 1.

Table 7. The parameter of HDE PSSs

\begin{tabular}{cccccc}
\hline & & $K_{1}$ & $K_{2}$ & $K_{3}$ & $K_{4}$ \\
\hline Scheme 3 & G2 & -5.25 & -0.39 & 50 & -1.96 \\
& G6 & -36.02 & 0.05 & 27.7 & 9.08 \\
Scheme 4 & G2 & -40.5 & 3.30 & 42.83 & 11.13 \\
& G5 & -37.3 & -7.12 & 15.59 & -9.84 \\
& G6 & -50 & -21.76 & 42.01 & -15.09 \\
Scheme 5 & G2 & -13.69 & 0.69 & 50 & 2.62 \\
& G5 & -36.26 & -8.34 & 17.05 & 3.98 \\
& G6 & -9.53 & -46.92 & 48.91 & 2.45 \\
\hline
\end{tabular}

disturbance to examine the time domain behaviors. Simulation results are given in Figures 14-16 for the generators 2 and 5 under three operating conditions. The system with scheme 5 can ensure good damping on oscillations under three operating conditions.

\section{Coherency analysis}

The coherency measures, described in Appendix $\mathrm{B}$, which are derived from time-domain responses, are proposed to evaluate the relative behaviors between any 


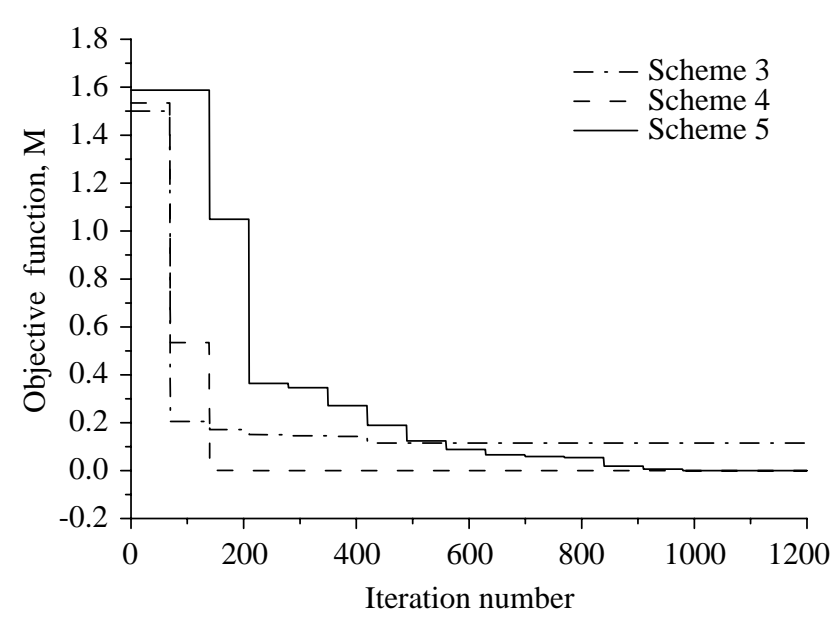

Fig. 8. Convergent characteristics of objective functions.

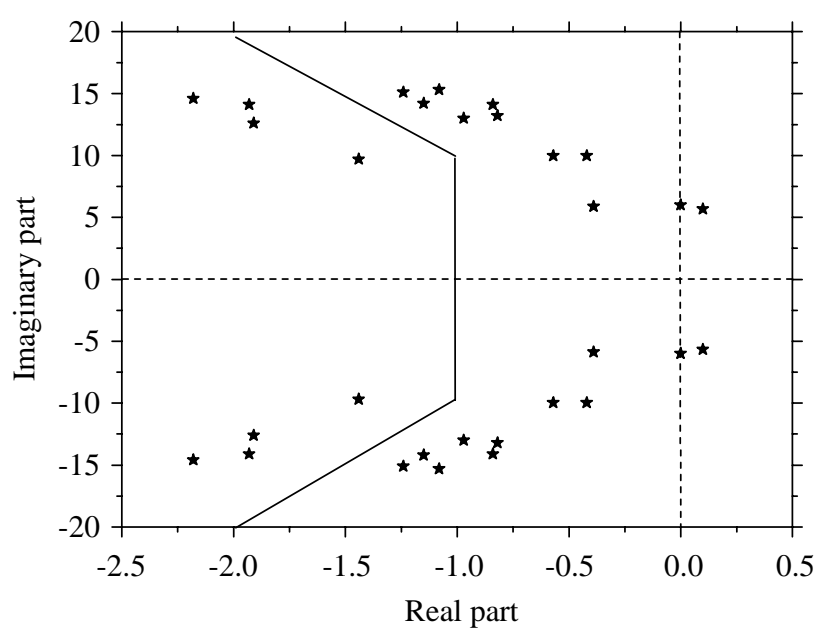

Fig. 9. Location of electromechanical modes of the system with scheme 1 under operation conditions 1-3.

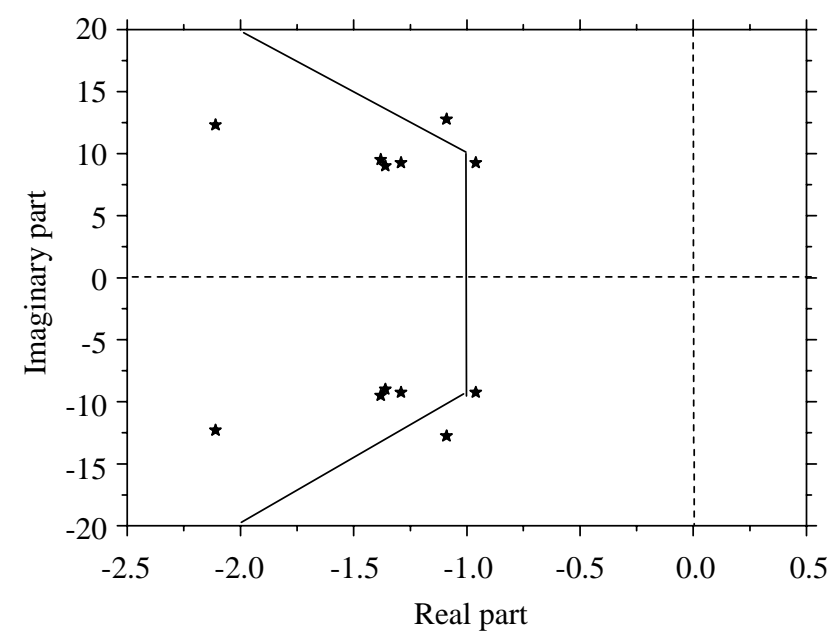

Fig. 10. Location of electromechanical modes of the system with scheme 2 under operation conditions 1-3.

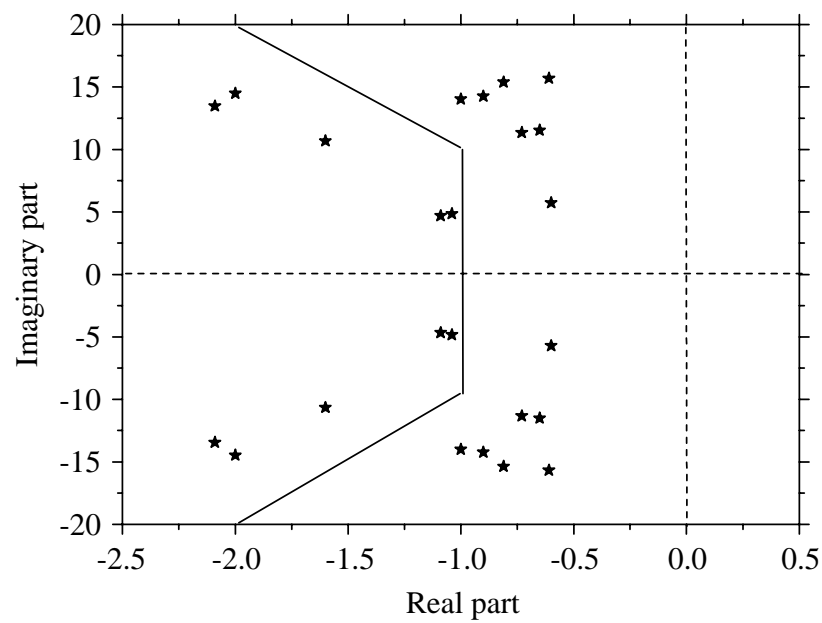

Fig. 11. Location of electromechanical modes of the system with scheme 3 under operation conditions 1-3.

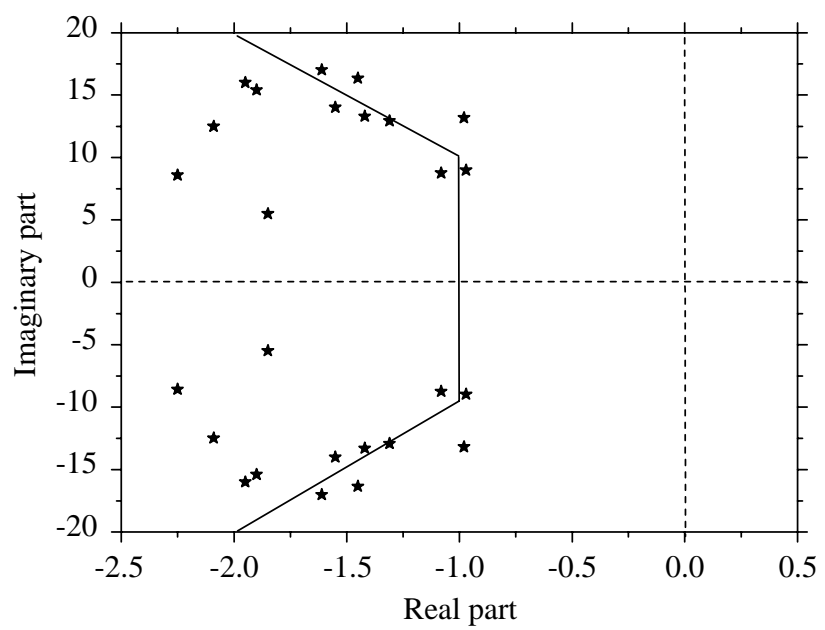

Fig. 12. Location of electromechanical modes of the system with scheme 4 under operation conditions 1-3.

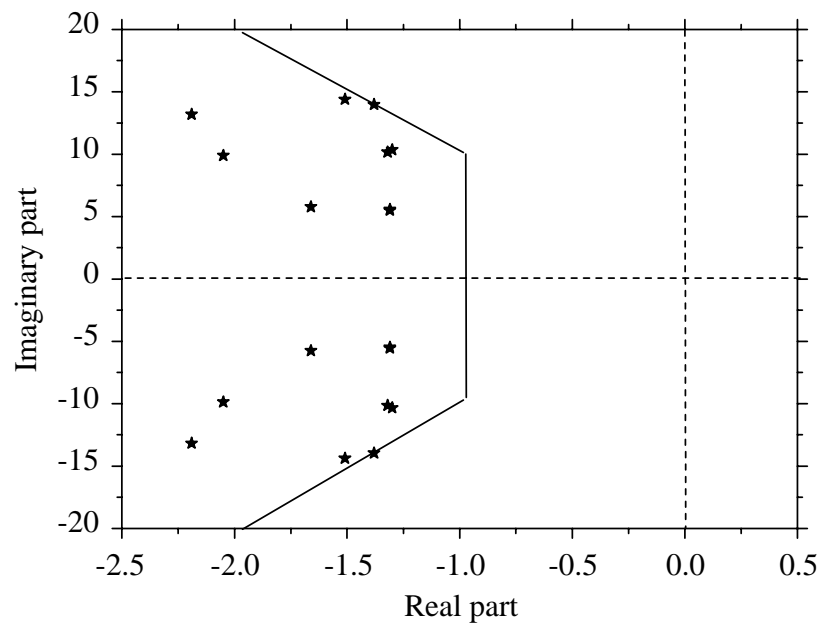

Fig. 13. Location of electromechanical modes of the system with scheme 5 under operation conditions 1-3. 

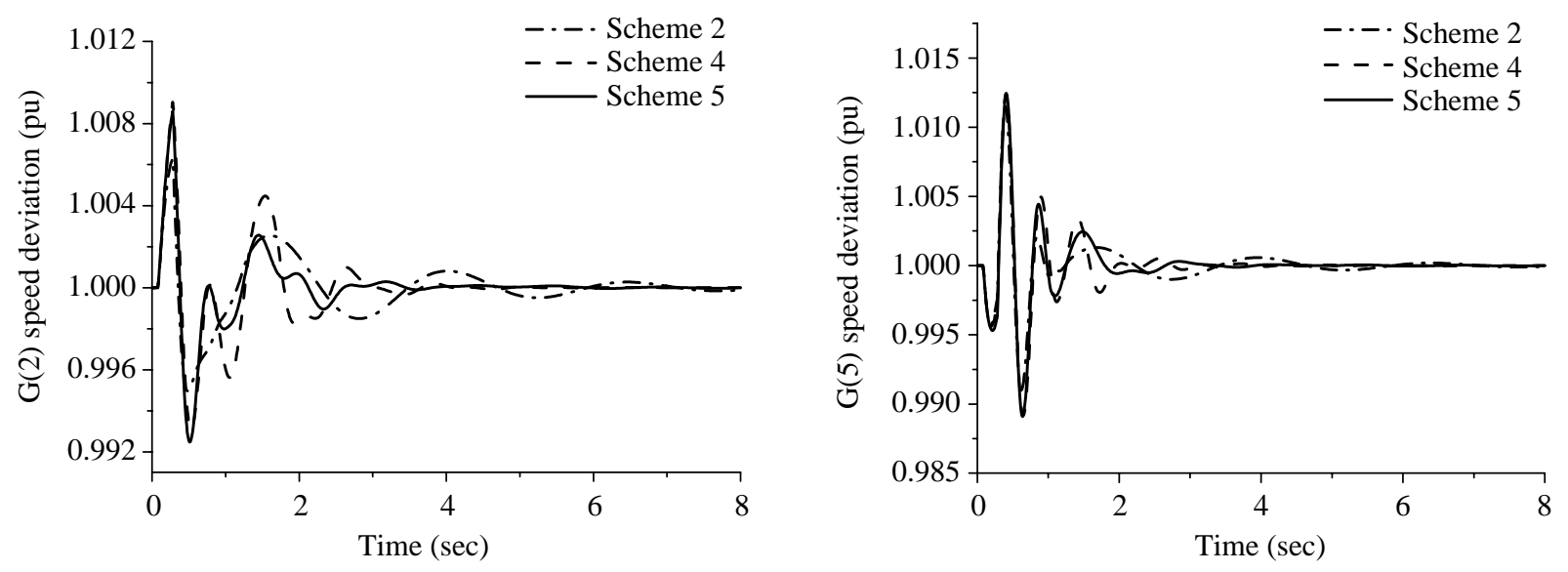

Fig. 14. Responses of Generators 2 and 5 under operating condition 1 subjected to large disturbance.
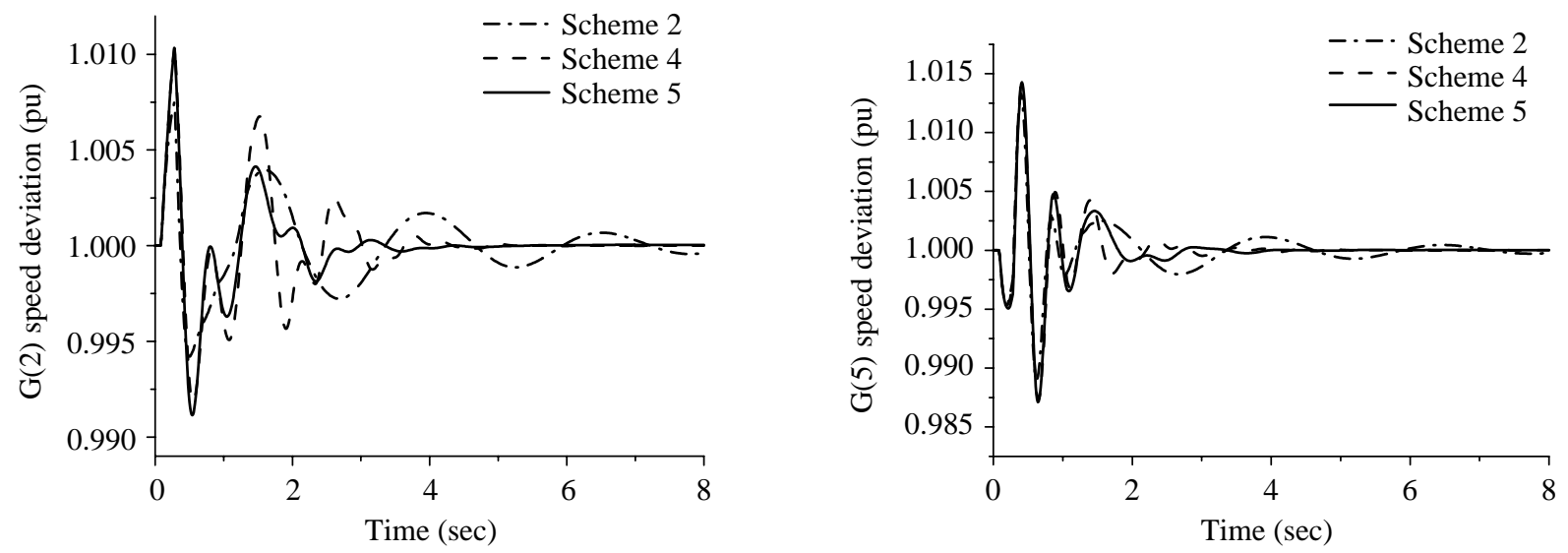

Fig. 15. Responses of Generators 2 and 5 under operating condition 2 subjected to large disturbance.
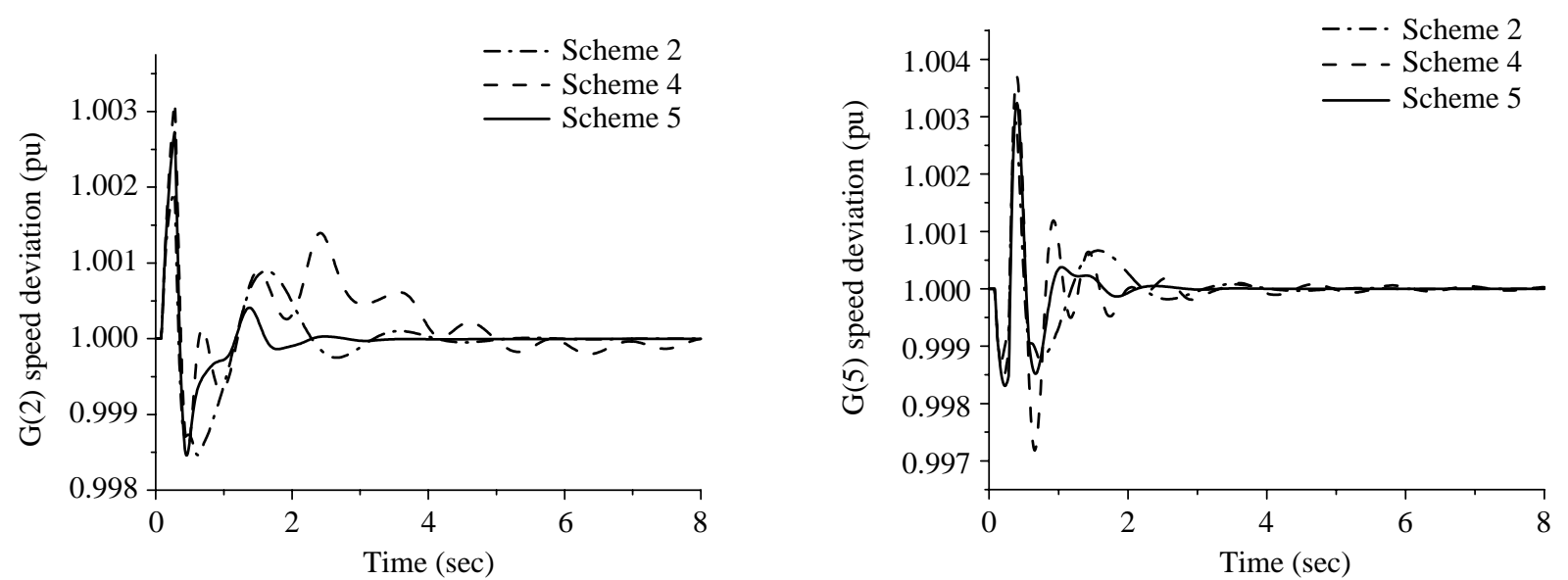

Fig. 16. Responses of Generators 2 and 5 under operating condition 3 subjected to large disturbance.

pair of generators. The results are given in Table 8 and Table 9 for the system without and with the PSSs of scheme 5, respectively. It can be found that the levels of similarity have been kept. For example, the values in
Table 8 show that $\mathrm{G} 2$ has a higher relation with G3. This situation also can be found in Table 9. Since the coherency behaviors do not be destroyed, the system should have a higher stability condition. 
Table 8. Coherency measures of the system without PSS

\begin{tabular}{cccccc}
\hline & G2 & G3 & G4 & G5 & G6 \\
\hline G2 & 1.0000 & 0.6706 & 0.2928 & 0.0000 & 0.4850 \\
G3 & 0.6706 & 1.0000 & 0.5918 & 0.0313 & 0.7733 \\
G4 & 0.2928 & 0.5918 & 1.0000 & 0.0811 & 0.7593 \\
G5 & 0.0000 & 0.0313 & 0.0811 & 1.0000 & 0.1602 \\
G6 & 0.4850 & 0.7733 & 0.7593 & 0.1602 & 1.0000 \\
\hline
\end{tabular}

Table 9. Coherency measures of the system with PSSs of scheme 5

\begin{tabular}{cccccc}
\hline & G2 & G3 & G4 & G5 & G6 \\
\hline G2 & 1.0000 & 0.5777 & 0.1409 & 0.0000 & 0.3432 \\
G3 & 0.5777 & 1.0000 & 0.3862 & 0.1538 & 0.5217 \\
G4 & 0.1409 & 0.3862 & 1.0000 & 0.1807 & 0.4880 \\
G5 & 0.0000 & 0.1538 & 0.1807 & 1.0000 & 0.2220 \\
G6 & 0.3432 & 0.5217 & 0.4880 & 0.2220 & 1.0000 \\
\hline
\end{tabular}

\section{CONCLUSION}

A decentralized pole placement method based on HDE has been successfully used in the design of output feedback power system stabilizers. A multi-machine system is used as an example to demonstrate the developed method and reveal the convergent procedures. The computation time and convergent characteristics of HDE are better, compared with that from GA and DE. It wants to guarantee a system with enough damping effects on oscillations over wide range of loading conditions. From the simulation results, the HDE gives a good method in tuning power system stabilizers to improve system dynamic stability. The coherency analysis results reveal that the levels of similarity between any pair of generators have been kept.

\section{REFERENCES}

1. Abdel-Magid, Y.L. and Abido, M.A., "Optimal Multiobjective Design of Robust Power System Stabilizers Using Genetic Algorithms," IEEE Transaction on Power Systems, Vol. 18, No. 3, pp. 1125-1132 (2003).

2. Abido, M.A., "Robust Design of Multimachine Power System Stabilizers Using Simulated Annealing," IEEE Transactions on Energy Conversion, Vol. 15, No. 3, pp. 297-304 (2000).

3. Abido, M.A., "Optimal Design of Power-System Stabilizers Using Particle Swarm Optimization," IEEE Transactions on Energy Conversion, Vol. 17, No. 3, pp. 406-413 (2002).
4. Abido, M.A. and Abdel-Magid, Y.L., "Robust Design of Multimachine Power System Stabilisers Using Tabu Search Algorithm," IEE Proceedings Generation, Transmission and Distribution, Vol. 147. No. 6, pp. 387-394 (2000).

5. Anderson, P.M. and Fouad, A.A., Power System Control and Stability, Iowa State University Press (1977).

6. Chiou, J.P. and Wang, F.S., "A Hybrid Method of Differential Evolution with Application to Optimal Control Problems of A Bioprocess System," Proceeding of the IEEE on Evolutionary Computation Conference, Anchorage, Alaska, pp. 627-632 (1998).

7. Hong, Y.Y. and Wu, W.C., "A New Approach Using Optimization for Tuning Parameters of Power System Stabilizers," IEEE Transactions on Energy Conversion, Vol. 14, No. 3, pp. 780-786 (1999).

8. Larsen, E.V. and Swann, D.A., "Applying Power System Stabilizers Part I, II, III," IEEE Transmission Power Apparatus System, Vol. 100, pp. 3017-3046 (1981).

9. Li, Y.C., Wang, F.S., and Hwang, K.S., "A Hybrid Method of Evolutionary Algorithms for Mixed-Integer Nonlinear Optimization Problems," Proceedings of the Congress on Evolutionary Computation, Washington, D.C., pp. 2159-2166 (1999).

10. Lin, U.C., Hwang, K.S., and Wang, F.S., "Plant Scheduling and Planning Using Mixed-Integer Hybrid Differential Evolution with Multiplier Updating," Proceedings of the Congress on Evolutionary Computation, La Jolla, CA, pp. 593-600 (2000).

11. Lin, Y.C., Hwang, K.S., and Wang, F.S., "Hybrid Differential Evolution with Multiplier Updating Method for Nonlinear Constrained Optimization Problems," Proceedings of the Congress on Evolutionary Computation, Honolulu, Hawaii, pp. 872-877 (2002).

12. Su, C.T. and Lee, C.S., "Modified Differential Evolution Method for Capacitor Placement of Distribution Systems," Proceeding of the Asia Pacific IEEE/PES Transmission and Distribution Conference and Exhibition, Yokohama, Japan, pp. 208-213 (2002).

13. Su, C.T. and Lee, C.S., "Network Reconfiguration of Distribution Systems Using Improved Mixed-Integer Hybrid Differential Evolution," IEEE Transactions on Power Delivery, Vol. 18, No. 3, pp. 1022-1027 (2003).

14. Tse, C.T., Wang, K.W., Chung, C.Y., and Tsang, K.M., "Parameter Optimization of Robust Power System Stabilisers by Probabilistic Approach," IEE Proceedings Generation, Transmission and Distribution, Vol. 147, No. 2, pp. 69-75 (2000).

15. Wang, F.S. and Jang, H.J., "Parameter Estimation of A Bioreaction Model by Hybrid Differential Evolution," Proceedings of the Congress on Evolutionary Computation, La Jolla, CA, pp. 410-417 (2000). 


\section{APPENDIX A: SYSTEM DATA (pu, except as indicated)}

The two-axis model describes the generator [5]. The power base is 100MVA.

Generator:

\begin{tabular}{lcccccccc}
\hline & $\begin{array}{c}\text { H } \\
(\mathrm{sec})\end{array}$ & $\mathrm{D}$ & $\mathrm{Xd}$ & $\mathrm{Xq}$ & X'd & X'q & $\begin{array}{c}\text { T'do } \\
\text { (sec) }\end{array}$ & $\begin{array}{c}\text { T'qo } \\
(\mathrm{sec})\end{array}$ \\
\hline G 2 & 6.4 & 0 & 0.8958 & 0.8645 & 0.1198 & 0.1969 & 6.0 & 0.535 \\
G 3 & 3.01 & 0 & 1.3125 & 1.2578 & 0.1813 & 0.25 & 5.89 & 0.6 \\
G 4 & 4.69 & 0 & 1.219 & 1.1695 & 0.1619 & 0.215 & 5.95 & 0.573 \\
G 5 & 4.7 & 0 & 1.2166 & 1.1742 & 0.1627 & 0.225 & 5.92 & 0.575 \\
G 6 & 4.71 & 0 & 1.2121 & 1.1789 & 0.1628 & 0.228 & 5.91 & 0.578 \\
\hline
\end{tabular}

Exciter:

\begin{tabular}{lcccc}
\hline & $\mathrm{K}_{\mathrm{A}}$ & $\begin{array}{c}\mathrm{T}_{\mathrm{A}} \\
(\mathrm{sec})\end{array}$ & $\begin{array}{c}\mathrm{K}_{\mathrm{F}} \\
(\mathrm{sec})\end{array}$ & $\begin{array}{c}\mathrm{T}_{\mathrm{F}} \\
(\mathrm{sec})\end{array}$ \\
\hline G 2 & 400 & 0.05 & 0.025 & 1.0 \\
$\mathrm{G} \mathrm{3}$ & 400 & 0.05 & 0.025 & 1.0 \\
$\mathrm{G} \mathrm{4}$ & 400 & 0.05 & 0.025 & 1.0 \\
G 5 & 400 & 0.05 & 0.025 & 1.0 \\
G 6 & 400 & 0.05 & 0.025 & 1.0 \\
\hline
\end{tabular}

Excitation voltage limits: $V \min =-7.3 \quad \mathrm{Vmax}=7.3$ PSS output limits: Vmax $=0.1 \quad$ Vmin $=-0.1$

Transmission line:

\begin{tabular}{cccccc}
\hline Line no. & From & To & $\mathrm{R}$ & $\mathrm{X}$ & $\mathrm{B} / 2$ \\
\hline 1 & 1 & 10 & 0 & 0.0576 & 0 \\
2 & 2 & 7 & 0 & 0.0625 & 0 \\
3 & 3 & 9 & 0 & 0.0586 & 0 \\
4 & 4 & 12 & 0 & 0.0605 & 0 \\
5 & 5 & 13 & 0 & 0.0605 & 0 \\
6 & 6 & 14 & 0 & 0.0605 & 0 \\
7 & 10 & 13 & 0.01 & 0.085 & 0.088 \\
8 & 7 & 13 & 0.032 & 0.161 & 0.153 \\
9 & 9 & 14 & 0.039 & 0.17 & 0.179 \\
10 & 12 & 14 & 0.017 & 0.092 & 0.079 \\
11 & 7 & 8 & 0.0085 & 0.072 & 0.0745 \\
12 & 8 & 9 & 0.0119 & 0.1008 & 0.1045 \\
13 & 10 & 11 & 0.0085 & 0.072 & 0.0745 \\
14 & 11 & 12 & 0.0119 & 0.1008 & 0.1045 \\
\hline
\end{tabular}

\section{APPENDIX B: COHERENCY MEASURES}

Coherency measures, which are derived from timedomain responses, are proposed to evaluate the relative behaviors between any pair of generators. Consider the rotor angle time-domain response $\delta_{i}(t)$ of a certain generator $i$ during a system transient, which is often referred to as the swing curve. An approximate time derivative of $\delta_{i}(t)$, denoted as $\omega_{i}(t)$, can be obtained as

$$
\omega_{i}\left(t_{k}\right)=\frac{\delta_{i}\left(t_{k}\right)-\delta_{i}\left(t_{k-1}\right)}{t_{k}-t_{k-1}}
$$

where $t_{k}$ is the $k$ th sample instant. Note that $\omega_{i}(t)$ essentially depicts the shape of the swing curve.

Then the index $W_{i j}^{\prime}$ is defined for any possible pair of generators $i$ and $j$ by

$$
W_{i j}^{\prime}=\sum_{t_{k} \in[0, T]}\left|\omega_{i}\left(t_{k}\right)-\omega_{j}\left(t_{k}\right)\right|
$$

In (B2) the summation is taken for all the samples during the whole studied interval $[0, T]$. The index is further normalized to become

$$
W_{i j}=W_{i j}^{\prime} / \max \left(W_{i j}^{\prime}\right)
$$

The index $W_{i j}^{\prime}$ calculates the total distance between the swing curves of generator $i$ and generator $j$, and the index $W_{i j}$ measures the degree of difference in shapes.

Finally, the coherency measure $C_{i j}$ is obtained by

$$
C_{i j}=1-W_{i j}
$$

Obviously, $0 \leq C_{i j} \leq 1, C_{i i}=1$, and $C_{i j}=C_{j i}$. The association between the pair of generators $i$ and $j$ can be evaluated by the value of $C_{i j}$. A larger $C_{i j}$ indicates that generator $i$ and generator $j$ are more similar in the time domain. Therefore, the index $C_{i j}$ does concern the degree of similarity in shapes. 